\title{
ANÁLISE CRÍTICA DE “O LIVRO NEGRO DA PSICANÁLISE: VIVER E PENSAR MELHOR SEM FREUD"
}

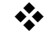 \\ Mayana Eliza Bracks Faria \\ Universidade Federal de São João del-Rei - UFSJ - Brasil \\ Roberto Pires Calazans Matos \\ Universidade Federal de São João del-Rei - UFSJ - Brasil
}

\begin{abstract}
Resumo
O presente artigo procura conduzir uma análise e um debate com base nas críticas feitas à psicanálise, as quais se encontram presentes na primeira parte da obra O Livro Negro da Psicanálise - Viver e Pensar melhor sem Freud. Cotejamos essas críticas com a letra do texto freudiano com a finalidade de averiguar se as mesmas são pertinentes. Delimitou-se à primeira seção por ela ter capítulos que compreendem uma dimensão importante para a teoria e para a clínica psicanalítica: a noção de sexualidade, além de melhor apontar quais são os pressupostos clínicos e epistemológicos que sustentam a crítica à psicanálise.
\end{abstract}

Palavras-chaves: Psicanálise, Livro Negro da Psicanálise, Epistemologia.

\section{Introdução}

O Livro Negro da Psicanálise foi publicado, originalmente, na França, no ano de 2005 e propunha empreender críticas à psicanálise, além de demonstrar as falhas de suas bases epistemológicas e clínicas. Dentro do contexto de pesquisas com pretensões científicas cuja premissa é o dispositivo da avaliação - questionários de opinião, quantificações, análises de resultados, entre outros - é comum encontrar exigências de eficácia e de eficiência (Miller e MILNER, 2006; AFLALO, 2012). É nele que as críticas do livro mencionado se endereçam à psicanálise. Seus autores a consideram uma prática não científica e, por isso, questionam a sua veracidade e eficiência. Para isso, buscam incessantemente critérios para definir, dentro do campo do sofrimento psíquico, o que seria uma psicoterapia baseada em evidências científicas. Dessa forma, a psicanálise deveria ser uma prática objetiva, sistemática e cientificamente comprovada. Somente com essas características é que uma prática poderia ter resultados satisfatórios para a sociedade. 
Os autores do Livro Negro afirmam que Freud fundamentou suas teorias no vazio (2012, p. 69) e, ao buscar eficácia terapêutica, colheu nada mais do que fracasso e teve como seguidores sujeitos que se orgulham por não obterem a cura (2012, p. 61). Para tais autores, Freud e os que adotam a psicanálise buscam imunizá-la contra qualquer tipo de avaliação ou verificação, mantendo assim, o 'mito' da superioridade psicanalítica (2012, p. 21/22). Acusam a psicanálise de desonestidade intelectual (2012, p. 11). Seguindo a direção dessa argumentação, os autores buscaram escrever O Livro Negro da Psicanálise como uma tentativa de expor outras maneiras de ver e de pensar e mostrar a verdade por trás da psicanálise.

Como essa verdade questionaria a validade da psicanálise? Com quais instrumentais teórico e clínico a criticam? Para responder a tais questionamentos, deteremo-nos na primeira parte de $O$ Livro Negro da Psicanálise, intitulada $O$ lado oculto da história freudiana, que contém artigos específicos de críticas aos textos e à fundamentação teórica de Freud. Nesse artigo, estaremos conduzindo um cotejamento das críticas presentes na primeira parte da obra com a letra do texto freudiano com a finalidade de averiguar se essas críticas são pertinentes. Decidimos nos centrar nessa seção do livro pela razão de terem capítulos que se reúnem em torno de uma dimensão importante tanto para a clínica quanto para a teoria psicanalítica: a questão da sexualidade. Escolhemos esses artigos, porque em torno deles poderemos apontar melhor quais são os pressupostos clínicos e epistemológicos que sustentam a crítica à psicanálise.

\section{Bases epistêmicas e terapêuticas do Livro Negro da Psicanálise}

As críticas à eficácia da clínica e à fundamentação da teoria psicanalítica de Freud não são propriamente novidade: a querela entre a psicanálise e outras abordagens data da época de Freud e encontra-se espalhada pelo mundo. Tais críticas, antes de tudo, buscam derrubar todas as suas bases, contrariando os fundamentos e pressupostos teóricos psicanalíticos com base em afirmações, muitas vezes, infundadas e em especulações.

Em uma longa sequência de críticas surge, em 2005, o Livro Negro da Psicanálise. Muitos argumentos contrários à psicanálise convenceram tanto o público leigo quanto os especialistas de que ela não detinha o saber que expressava, além de conter inverdades: "homens e mulheres inteligentes foram conquistados, pela psicanálise, pelo seu romantismo e pela sua linguagem misteriosa" (2012, p. 24). Esse trecho exemplifica o movimento que é feito por todo o livro, em que os autores tentam, a todo custo, sustentar que os conceitos freudianos seriam uma grande farsa disseminada por escritos mentirosos. 
Ao buscar refutar a teoria e prática psicanalítica, a obra francesa, organizada por Catherine Meyer, reúne 23 autores de sete nacionalidades contrários a tal abordagem. Há quatro autores cujo papel é mais decisivo, como Mikkel Borch-Jacobsen, Jean Cottraux, Diddier Pleux e Jacques Van Rollaer, tornando mais acessível ao público leigo elementos para um debate acerca do assunto, possibilitando aos pacientes a palavra e a voz que muitas vezes é esquecida nos debates.

A tradução brasileira de $O$ Livro Negra da Psicanálise, que será utilizada nesse artigo, publicada em 2012, foi realizada por Simone Perelson e conta com um número menor de artigos. A tradutora buscou manter, a característica "bélica" (2012, p.18) do livro, escolhendo os artigos por meio de um suposto rigor teórico, isto é, aqueles que suscitariam uma discussão mais profunda e mais conceitual. Simone Perelson julga relevante a publicação dessa obra para o Brasil, pois a publicação do original levou a França a uma discussão importante: fez com que os teóricos franceses explicassem e esclarecessem aos leigos as bases da teoria e da clínica psicanalítica em contextos públicos e midiáticos.

As reações contrárias ao livro foram diversas e não tardaram a chegar. Ainda em 2005, Elizabeth Roudinesco lançou o primeiro livro em defesa da psicanálise, nomeado Por que tanto ódio? Anatomia do livro negro da psicanálise. Para a autora, há, no Livro Negro da Psicanálise, "números falsos, afirmações inexatas e interpretações por vezes delirantes" (2005, p. 21), o que acarretou um questionamento do ódio dos autores pela teoria e prática psicanalítica, colocando a psicanálise como responsável por um suposto massacre. Roudinesco definiu O Livro Negro da Psicanálise como "um requisitório fanático que se situa na tradição da escola dita 'revisionista [1]," (2011, p. 19).

Em 2006, foi a vez de Jacques-Alain Miller lançar o livro coletânea O Anti-livro Negro da Psicanálise, em que se denuncia que por trás da dita crítica interdisciplinar uma erapia que se destaca: a terapia cognitivo-comportamental. Para Miller (2006), O Livro Negro da Psicanálise, antes de ser um balanço da psicanálise, tem propósitos mais políticos do que acadêmicos e, por isso, a resposta de O Anti-livro Negro da Psicanálise não seria somente epistêmica: ele não defende, mas sim ataca. Ele não somente defende Freud e a psicanálise contra um pout-pourri de reclamações tão torturantes quanto inoperantes. Já em 2012, Agnès Aflalo publicou $O$ assassinato frustrado da psicanálise, em que faz um panorama da origem e dos meandros do que se configuraria, mais tarde, como a tentativa de acabar ou de expor as ‘inverdades' sobre a psicanálise e faz uma defesa da mesma. 
O Livro Negro da Psicanálise é um livro acontecimento e seus autores o consideram o mais exaustivo balanço crítico da psicanálise cujo resultado seria divulgar as ditas inverdades sustentadas por Freud. Eles buscaram revelar a inferioridade da eficácia curativa da psicanálise em relação a outras terapias, como por exemplo, as Teorias Cognitivas Comportamentais (TCCs). Cabe a nós, então, nesse momento, indagar em que bases terapêuticas e epistemológicas essas críticas são feitas.

Em termos epistemológicos, podemos dizer que a base do Livro Negro não é a ciência e sim o cientificismo. Para Aflalo (2012, p. 12), cientificismo é uma "ideologia da avaliação", em que o homem é um objeto calculável, cujo corpo tanto físico quanto psíquico é reduzido a uma "maquinaria reificada" (2012, p. 12). Nessa mesma direção, Calazans e Lustoza (2008, p. 126) afirmam que "o cientificismo seria a crença de que as ciências naturais poderiam fornecer uma orientação ética para o devir humano em geral". Há uma pressão da sociedade de obter respostas científicas que levem os sujeitos a ficarem presos a uma ideologia de fatos comprovados sem questioná-los, mesmo que eles não digam respeito ao problema tratado. É nesse contexto que as práticas psicoterápicas com pretensões científicas desenvolvem e ganham destaque (DACORSO, 2005, p. 123), sinalizando que os esforços se concentram somente no querer encontrar experimentalmente as repostas para todas as perguntas e questionamentos, inclusive o que diz respeito ao psiquismo (Ferrari, 2002, p. 83). No entanto, quando estamos lidando com o sujeito e o seu sofrimento psíquico, será que cabe o método que valoriza a aplicação de questionários, quantificações, avaliações e análises estatísticas de resultados?

A psicanálise, cujo rigor teórico está livre do cientificismo (Lévy, 2009, p. 10), encontra no sintoma do sujeito articulado no campo da fala e da linguagem a essência de sua descoberta. Diferentemente do que é visto dentro da sociedade experimental e científica, a psicanálise e o tratamento psicanalítico são desenvolvidos por meio da fala, da associação livre - sua regra fundamental. O método de associação livre é o caminho estabelecido para se alcançar o objeto da psicanálise, o inconsciente. O processo psicanalítico é construído caso a caso, em cada encontro, para cada paciente, sendo esta uma clínica singular, a clínica do sujeito. A fala "é agente de cura, de formação ou de sondagem" (Lacan, 1953/1998, p. 112). A fala, equivalente a uma confissão, ocupa um lugar de extrema importância nos tratamentos psíquicos e possibilita ao paciente um tratamento, uma libertação (Roudinesco, 2011, p. 60). Por ser uma experiência do campo da linguagem, a psicanálise vai buscar teorizar a estrutura dessa experiência, bem como desenvolver a sua clínica com base no discurso do sujeito. A psicanálise se situa na esfera da ética, apoiando-se na especificidade do sujeito e de sua estrutura clínica, além de se amparar 
nos princípios de sua prática. O ato do analista é que dá existência ao inconsciente promovendo a psicanálise no singular de cada caso (Quinet, 2009, p.8).

Postas as bases terapêuticas e epistêmicas do Livro Negro da Psicanálise, passemos agora às asserções que encontramos em sua primeira parte, principalmente as que se endereçam à questão da sexualidade.

\section{Críticas do Livro Negro e algumas respostas à luz da Psicanálise}

A primeira parte do Livro Negro da Psicanálise tem como título O lado oculto da história freudiana. Limitaremo-nos aqui à primeira parte por ela ter um tema em comum: a noção de sexualidade e seu lugar na obra e na clínica de Freud. A primeira parte, então, é dividida em três seções: Mitos e Lendas da Psicanálise, As falsas curas e A fabricação dos dados psicanalíticos e são compostas por capítulos de artigos e entrevistas que resenham parte da obra de Freud por meio de análises do desempenho dele em relação à elaboração e desenvolvimento da psicanálise. Dotados de uma escrita construída sem embasamento ou rigor epistêmico, e sim em estilo panfletário, os autores do Livro Negro da Psicanálise caracterizam Freud como um contador de histórias e coloca a Psicanálise como um mito, uma lenda: "O fundador da psicanálise era verdadeiramente um escritor que sabia como construir uma intriga, animar personagens, tornar vivos os conceitos" (2012, p. 31). Freud é acusado de manipular sua narrativa para garantir para si sucessos que seriam somente historietas sem fundamentação científica.

A obra em questão pretende ser argumentativa, porém não é isso que encontramos. Argumentos fracos, ironias e suposições fazem parte dos textos estudados. Veremos a seguir alguns exemplos através da exposição de alguns capítulos. O primeiro, intitulado Era uma vez, escrito por Mikkel Borch-Jacobsen, trata-se de um resumo da obra de Freud e nele já se encontra o movimento especulativo e irônico do livro: ao falar da questão da sexualidade, Jacobsen diz que Freud se viu forçado a reconhecer sua importância "apesar de seu pouco gosto pela coisa" (2012, p.33). Esse resumo faz o percurso de Freud de 1882 até 1900 de maneira confusa e precipitada, passando metonimicamente por métodos formulados por Freud, tais como o hipnótico-catártico e o das hipóteses de que as histéricas sofriam de reminiscências, em que seria possível "curá-las fazendo reviver e verbalizar essas lembranças sob hipnose" (2012, p.33). Jacobsen aborda a hipótese sexual que levou a ruptura entre Freud e Breuer e as correspondências de Freud com Fliess acerca da teoria da periodicidade dos dois sexos e de 
como isso levou à associação livre. Aborda ainda a teoria da sedução traumática e como rapidamente ela fora abandonada.

O uso do estilo metonímico de Jacobsen é mais frequente em provocação do que em debates sérios sobre qualquer tema. As passagens ligeiras de uma a outra elaboração freudiana sem pensar seus impasses, os problemas aos quais Freud estava se deparando é próprio de quem está a construir um adversário e não debatendo ideias. Podemos dizer que Jacobsen avalia Freud se valendo de uma epistemologia do tudo ou nada: se a hipótese se confirma, ela acertará sempre desde o início. É nessa direção que vemos a leitura de determinadas formulações: Freud fundamenta a cura e a teoria psicanalítica na talking cure. Se ela é falseada, logo toda a psicanálise é falseada. Ora, epistemologicamente não existe ciência que surja de pronta a partir de suas hipóteses fundamentais. Como diz Gaston Bachelard (1996), a ciência sempre encontra avanços, retrocessos, pontos de detenção. Por que com a psicanálise seria diferente? As diversas revisões, retomadas, avanços de Freud não ilustram isso? O próprio Freud admite no prefácio à segunda edição que houve modificações na teoria.

Os desenvolvimentos e mudanças ocorridos em meus pontos de vista
no decorrer de treze anos de trabalho foram extensos demais para que
seja possível vinculá-los a minha anterior exposição sem destruir
inteiramente seu caráter essencial. Tampouco tenho qualquer motivo
para desejar eliminar esta prova de meus conceitos iniciais. Ainda
hoje não os considero erros, mas como valiosas primeiras
aproximações de um conhecimento que só poderia ser plenamente
adquirido após longos e continuados esforços. (Freud, 1893/1895
[1996], p.35).

Os autores do Livro Negro da Psicanálise têm necessidade de buscar dados e fatos históricos para repelirem a hipótese freudiana. No entanto, essa epistemologia não resiste a dois testes: o da lógica e o da história. É o que Alexandre Chalmers (1999) denomina de falsificacionismo: tem por premissa que uma hipótese só pode ser considerada válida se ela sobreviver ou aos experimentos ou ao teste da observação. No que diz respeito à lógica, Chalmers faz a seguinte questão: por que entre a hipótese e a observação, a hipótese que deve ser abandonada? O autor alia a esse questionamento lógico um exemplo histórico:

Nada na lógica da situação requer que deva ser sempre a teoria a ser rejeitada num choque com a observação. Uma proposição de observação falível pode ser rejeitada e a teoria falível com a qual ela se choca ser mantida. (...). A ciência abunda com exemplos de rejeição de proposições de observação e retenção de teorias com as quais elas se chocam. Contudo, por mais seguramente baseada na observação uma afirmação possa parecer estar, a possibilidade de que novos avanços teóricos revelarão inadequações nessa afirmação não 
pode ser descartada. Consequentemente, falsificações conclusivas, diretas, de teorias, não são realizáveis. (Chalmers, 1999, p.91).

Sobre a cura das histéricas, a palavra de Freud e Breuer demonstra que, longe de afirmar a cura, naquele momento, afirmou-se apenas a remissão dos sintomas devido à incipiência da pesquisa. Freud e Breuer trazem um primeiro elemento explicativo para o tratamento da histeria, mas a cura dependeria do aspecto etiológico. O trauma seria uma condição secundária. Lidar com eles daria conta de destituir os sintomas, mas a cura deveria vir com cessão da causa.

É a noção de causa da histeria que leva à ruptura entre Freud e Breuer. Não é somente a noção da sexualidade, mas também a divergência sobre se somente as causas acidentais seriam suficientes. Ora, aqui já podemos notar um primeiro problema a esse tipo de crítica: é sabido que Freud substituiu o método hipnótico-catártico pelo da associação livre. É sabido também que Freud introduziu o método da associação livre com as suas críticas a esse método, o qual ele considerava limitado. Essas críticas já eram encontradas no último capítulo da obra Estudos sobre a Histeria (1895/1996), embora Freud ainda não tivesse desenvolvido tal método. Sustentar a crítica somente em torno da obra Estudos sobre a histeria é um modo de fazer a história desconsiderando os fatos da mesma.

Sobre o papel da sexualidade, vemos que a questão não é avaliada de maneira apropriada. Como demonstraram Foucault e Lantéri-Laura, a sexualidade estava na ordem do dia no campo das questões psicopatológicas. Diversos autores que estavam às voltas com a questão da psicopatologia, no século XIX, preocupavam-se com a questão da sexualidade, sendo esta vista como uma atividade fundamentalmente humana ${ }^{[2]}$. Freud não podia ignorar isso. A novidade proposta por esse psicanalista não está em considerar a sexualidade em seus estudos e sim a criação de um novo conceito que proporcionou uma ruptura epistemológica com a ordem vigente [a sexologia], ampliando e modificando a noção de sexualidade a uma disposição psíquica universal, além do rompimento com o seu fundamento biológico, anatômico e genital.

A sexualidade infantil é o conceito que Freud extrai para pensar, pautada em sua experiência clínica por meio da escuta do sujeito, sobre o lugar da sexualidade como causa das neuroses. Foi em 1905, a partir do livro Três ensaios sobre a teoria sexual e dos estudos sobre as perversões que Freud concluiu que a sexualidade humana tem uma disposição perversa, no sentido de que a sexualidade estará sempre além da mera genitalidade. Isso permitiu lhe considerar as atividades infantis em uma nova dimensão, cujas manifestações são tidas como etapas do desenvolvimento da sexualidade infantil desde o início da vida e não somente na 
puberdade, conforme era proposto na época (André, 1998). A sexualidade deixa o contexto das perversões para se inscrever no campo pulsional e do desejo (André, 1998). Não se trata, a luz da teoria freudiana, da sexualidade como o ato sexual nem a sexualidade como um fator meramente anatômico. Trata-se da sexualidade em duas dimensões: a que comporta uma satisfação pulsional e a que implica uma relação com o Outro como alteridade.

A questão da sexualidade e sua articulação com a psicopatologia não era algo que surgiu somente em Freud ou em uma preferência dele. Era algo que estava na ordem do dia. Os capítulos seguintes dessa seção, como veremos, fazem acusações de mistificação à psicanálise e ignoram que além dessa preocupação, que não era somente de Freud, a era insuficiente e errôneo considerar a sexualidade restrita e exclusivamente à genitalidade.

O segundo capítulo da primeira sessão, A verdade sobre o caso da senhorita Anna O., também de autoria de Mikkel Borch-Jacobsen, marca a crítica feita à obra Estudos sobre histeria (1893/1996) e tem como introdução a seguinte frase: (A história é admirável, da mesma forma que seu principal herói. O problema é que se trata de uma lenda - a 'lenda freudiana' (...), não há praticamente um único desses elementos que não seja ficção) (2012, p. 37). Jacobsoen utiliza-se de argumentos e de questionamentos feitos por Ernest Jones e por Henri Ellenberger para sustentar a sua própria crítica e para demonstrar que a questão sexual é uma imposição de Freud e de Breuer à histeria.

O primeiro questionamento foi feito por Ernest Jones em uma biografia sobre Freud lançada em 1953. Jones revela que o tratamento de Anna O. não foi finalizado com sucesso, ou seja, não houve uma cura, conforme informado na obra freudiana. Aconteceram recaídas e a paciente foi internada algumas vezes antes de se estabelecer por completo. Anos mais tarde, foi a vez de Henri Ellernberger suscitar alguns questionamentos. Segundo o historiador da psiquiatria, a biografia de Ernest Jones não era confiável, por isso iniciou sua própria pesquisa. Ellernberg encontrou registros de documentos assinados por Breuer e pelo diretor da clínica que comprovariam as internações prolongadas de Anna O. e a permanência de seus sintomas histéricos (2012, p. 40/41). Para ele, Anna O. ainda sofria de alucinações quando Breuer publicou um artigo apontando o sucesso adquirido com o método de tratamento. Relembra ainda que, em 1883, Freud enviou uma carta à noiva dele na qual menciona as dificuldades do tratamento e conta que Breuer teria se apaixonado por sua paciente, o que levou a interrupção do tratamento. Jacobsen faz disso o ponto de sua crítica, ao afirmar que Freud teria invertido os papéis dos personagens do tratamento e teria sugerido a natureza sexual da histeria e assim teria desenvolvido o conceito fundamental para a psicanálise: amor transferencial. 
Segundo Jacobsen, tanto para Ernest Jones quanto para Henri Ellernberger, teria havido uma interpretação arbitrária de tudo o que aconteceu com Anna O.: para Ellenberger, se a paciente curou-se, não foi devido à "talking cure”, o que não permitiria a Freud fazer do caso de Anna O. o fundador da psicanálise. Para Jacobsen, Freud e Breuer usaram Anna O. para promover o método baseado em conclusões embaraçosas e atribuíram o mérito todo para si contra toda e qualquer credibilidade (2012, p. 42).

Deve-se considerar se essa afirmação é verdadeira. Em sua obra, Estudos sobre a Histeria, Freud realizou o desenvolvimento de uma teoria ainda incompleta sobre a histeria e sobre a fundamentação de um método de tratamento da mesma. O caso da Anna O. possibilitou, portanto, a compreensão de que o psíquico manifesto do paciente não é o psíquico em sua totalidade e que o tratamento ampara-se por meio da fala. Ou seja, a teoria que comandava o tratamento de Anna O. era a primeira formulação de Freud sobre a histeria escrita em colaboração com Joseph Breuer, de 1893-1895, em que o método terapêutico utilizado era o método catártico. Esse procedimento pressupunha que o paciente fosse hipnotizado e, dessa forma, o seu consciente seria ampliado, tendo como objetivo a eliminação dos sintomas (Freud, 1904[1903]).

Essa obra, para tanto, encontra-se na pré-história da teoria psicanalítica, pois possibilitou a elaboração de conceitos fundamentais como inconsciente, sonho, recalcamento, mecanismos de defesa, resistência, conversão e a própria histeria, como proporcionou também o desenvolvimento de uma clínica freudiana. Buscava-se compreender o mecanismo psíquico dos fenômenos histéricos e uma possível explicação das paralisias hístero-traumáticas. Mais tarde, Freud abandona esse método catártico por considerá-lo sugestivo. Por meio de observações de casos clínicos, Freud constatou que havia muitos limites, como a dificuldade em utilizá-lo em todos os pacientes, a dificuldade que os pacientes tinham em rememorar fatos importantes da vida devido ao esquecimento sugerido, o fato de que o método escondia a resistência do paciente e, consequentemente, não a anulava em relação à sua representação, além de que o paciente não tinha condições de promover uma elaboração associativa referente ao evento lembrado. Ainda não se tinha o conceito de transferência, que iria surgir propriamente como conceito, somente na década de 1910. Freud tateava na formulação da sexualidade como fator causal: não temos aí a ideia de uma sedução traumática e muito menos de uma sexualidade infantil. Jacobsen toma dados de realidade, mas os interpreta para além da lógica interna da teoria de Freud e de Breuer em Estudos sobre a Histeria. Principalmente, Jacobsen ignora que a importância da sexualidade na histeria não era algo pioneiro das teorias freudianas. 
Se o caso Anna O. fosse paradigmático da psicanálise, Freud não abandonaria o método que o sustentava - hipnótico-catártico - para desenvolver o método de associação livre que permite ao sujeito falar sem censura, sem necessidade de se entregar a um sono artificial (Freud, 1904[1903]). As conclusões de Freud não foram embaraçosas como Ellernberger afirma, pois sua pesquisa não parou em Estudos sobre a Histeria. Freud não colocou os conceitos sobre histeria e tantos outros como verdades incontestáveis. Há uma construção de conhecimento em andamento. A prática psicanalítica depende do afinamento singular do desejo do sujeito e não de uma padronização específica. Como clínica, ela avança entre o universal da teoria e o específico do caso clínico (Ansermet, 2005).

O capítulo seguinte, desenvolvido por Allen Esterson, A teoria da sedução: um mito para o nosso tempo, coloca a psicanálise como uma história completa de relatos míticos, sendo a teoria da sedução traumática o mito mais resistente até hoje (2012, p. 49). O autor impressiona ao dizer que ela ainda resistente, uma vez que essa é a teoria foi abandonada por Freud em 1897, ou seja, não pode ser resistente até hoje.

Segundo Allen Esterson (2012, p. 50), na obra freudiana, as pacientes teriam relatado que foram vítimas de abuso sexual na primeira infância e que, em sua grande maioria, eram perpetrados pelos pais. Na tentativa de explicar e de provar a veracidade do seu ponto de vista, Freud escreveu que essas recordações inconscientes recalcadas são a raiz dos sintomas dos pacientes histéricos.

Freud descobriu que os relatos de suas pacientes não eram verdadeiros e tratavam-se de fantasias incestuosas: Freud formulou a teoria da sedução traumática como sendo esta a causalidade sexual da histeria e a primeira hipótese do recalque. A neurose histérica, portanto, teria sua origem no trauma desenvolvido na relação de abuso sexual real, ocorrendo geralmente na primeira infância. A lembrança dessa cena ou do trauma era penosa e angustiante para o sujeito, que preferia esquecê-la ou recalcá-la. O abandono da teoria da sedução levou-o à elaboração da causa da histeria, publicada em A interpretação dos sonhos em 1900: o conflito psíquico inconsciente, ou seja, o trauma. A partir desse momento, já não exercia a base da explicação sobre a sexualidade humana.

Freud abandonou a teoria da sedução traumática em 1897, após se deparar com algumas situações: nem todos os pais são violentadores e as histéricas não estão mentindo ao afirmar que eram vítimas de uma sedução. Dessa forma, Freud propôs a elaboração de uma realidade psíquica baseada fundamentalmente no inconsciente, lugar em que se privilegia o registro da imaginação e das fantasias sem considerar o que é vivenciado na ordem do real. 
Para Allen Esterson (2012), Freud nunca escutou os relatos de abuso, já que as pacientes não os haviam sofrido. O que aconteceu foi uma suposta influência durante o processo terapêutico na busca desenfreada de tentar explicar a sua descoberta por meio da fantasia inconsciente dos pacientes (2012, p. 49). Para o autor, Freud não teria condições de decidir se suas reconstruções analíticas representavam recordações recalcadas de acontecimentos reais ou fantasias inconscientes, ou ainda, de roteiros plenos de imaginação tirados do seu próprio espírito (2012, p. 52). A teoria da sedução foi rotulada por Allen Esterson como uma história falsa em sua essência, ameaçando assim, a credibilidade das outras teorias desenvolvidas posteriormente. Esterson se atém a uma teoria já abandonada pelo próprio Freud, o que não significa que a mesma não tenha sido importante no desenvolvimento da Psicanálise.

No último capítulo dessa seção de $O$ Livro Negro da Psicanálise há uma entrevista com Han Israels, intitulada A teoria da sedução: uma ideia que não funcionou. De acordo com Israels, Freud deveria ter agido diferentemente com suas pacientes, pois deveria ter acreditado nelas ao invés de duvidar de suas narrativas (2012, p. 58). Com a teoria da fantasia, segundo Israels, Freud não acreditaria em suas pacientes (2012, p. 59).

Devemos, antes de mais nada, voltarmo-nos para a teoria de Freud e lermos atentamente sobre o que é fantasia para o autor, sendo este um conceito importante para a teoria psicanalítica. Freud (1893/1895 [1996]), ao chamar de fantasia, não estava duvidando de suas pacientes. No tratamento da histeria, Freud deparou-se, através dos relatos clínicos, com uma realidade que não podia ser considerada real, e sim psíquica. As histéricas, sujeitos submetidos ao desejo do Outro, tinham suas cenas narradas como uma ficção que dá estrutura à verdade, traumatizam e fazem sintoma. Freud, em 1919, afirma que a fantasia remete a uma cena difusa que teria acontecido na primeira infância e que tem um efeito traumático ao sujeito. A fixação do sujeito é devido a impressões em situações cotidianas que só podem interessar a um único sujeito. Portanto, a fantasia é da ordem do singular, e não do universal.

\section{Conclusão}

Freud buscava compreender e examinar o mecanismo psíquico dos fenômenos histéricos e, partindo daí, elaborou e construiu conceitos que seriam os pilares de sua teoria. Os conceitos, como também seus métodos, foram sendo modificados e reelaborados conforme a sua clínica e seus estudos. Freud chega à regra fundamental da psicanálise: a associação livre e propõe o uso da palavra de modo que esta se torne a via de acesso ao inconsciente - o cerne a questão do sujeito opera a nível da linguagem. 
O processo psicanalítico, logo, é construído caso a caso, em cada encontro, para cada paciente, sendo esta uma clínica singular, uma clínica do sujeito. A fala "é agente de cura, de formação ou de sondagem" (Lacan, 1953/1998, p. 112). Foi preciso que Freud percorresse um caminho marcado pela escuta para que viesse a formular conceitos importantes, como o de inconsciente, de sexualidade, de transferência, de resistência, dentre tantos outros.

É por essa razão que a legitimidade teórica da psicanálise é constantemente questionada, questionam a sua eficácia nos tratamentos e acusam as teorias freudianas de inconsistência e desonestidade intelectual. Os autores de O Livro Negro da Psicanálise fizeram análises incompletas das teorias freudianas e tentaram desabilitar a prática psicanalítica a todo custo exigindo que a psicanálise seja uma prática objetiva, sistemática e não levaram em consideração a epistemologia psicanalítica. Para eles, Freud não passava de um bom contador de histórias e de um excelente publicitário que soube vender o seu produto, mesmo tendo, segundo esses autores, encontrado somente fracasso (2012, p. 69). Apontamos em nosso texto que a noção epistemológica de fracasso e a noção psicanalítica de sexualidade nos permitem traçar outra análise das elaborações de Freud e estas não passam pela perspectiva cientificista, mas apontam para o fato de que quando estamos às voltas com um sujeito, precisamos de conceitos mais pertinentes do que os de eficácia e eficiência.

É importante deixar claro que ao se pensar a coerência interna de uma teoria é necessário compreender as coordenadas internas a ela própria, sem usar critérios de avaliação que não lhe cabem. É equivocado buscar compreender uma teoria por imposições de referenciais externos à mesma. $\mathrm{O}$ grande problema encontrado nas críticas presentes à psicanálise é o fato de usarem critérios de avaliação de um campo de saber, nesse caso o dito científico, para pensar sobre os limites e possibilidades de outro campo de saber. É supor um modo de avaliação que seja rigoroso e controlado, sem respeitar as individualidades do campo que se critica.

\title{
CRITICAL ANALYSIS OF "BLACK BOOK OF PSYCHOANALYSIS : LIVE AND THINK BETTER WITHOUT FREUD"
}

\begin{abstract}
This article tries to conduct an analysis and discussion from the psychoanalysis' criticism which are present in the first part of the book The Black Book of Psychoanalysis - Living and Thinking better without Freud. It was used freudian text to reveal if those criticisms are relevant or not. It was delimited to the first section because those chapters are constituted with an important dimension to the psychoanalytic theory and to psychoanalytic clinic: the notion of sexuality, pointing out what are the best clinical and epistemological assumptions that sustain the psychoanalysis' review.
\end{abstract}

Key-words: Psychoanalytic, The Black Book of Psychoanalysis, Epistemology. 


\title{
EL ANÁLISIS CRÍTICO DEL LIVRO NEGRO DEL PSICOANÁLISIS - VIVIR, PENSAR Y ESTAR MEJOR SIN FREUD
}

\begin{abstract}
Resumen
Este artículo busca conducirunanálisis y una discusión a partir de las críticas hechasalpsicoanálisis que estánenlaprimera parte deltrabajo El Libro Negro delPsicoanálisis Vivir, pensar y estar mejorsin Freud. Comparamos estas críticas conla letra del texto freudiano conlafinalidad de averiguar si estas críticas son válidas. Fue delimitada laprimerasecciónpuesellacontiene capítulos que dicenrespeto de una dimensión importante para lateoría y prácticapsicoanalítica: lanoción de sexualidad, apuntandoasícualessonlospresupuestos clínicos y epistemológicos que sostienenla crítica al psicoanálisis.
\end{abstract}

Palabras clave: Psicoanálisis, El Libro Negro de Psicoanálisis, Epistemología.

\section{Referências Bibliográficas}

AFALO, Àgnes. O assassinato frustrado da psicanálise. Rio de Janeiro: Contra Capa, Opção Lacaniana, n. 9, 2012.

ANDRÉ, Serge. O que quer uma mulher?.Rio de Janeiro: Jorge Zahar Ed., 1998.

ANSERMET, François. A clínica da origem. Rio de Janeiro: Contra capa, 2005.

BACHELARD, Gaston. A formação do espírito científico. Rio de Janeiro: Contraponto, 1996

CALAZANS, R.; LUSTOSA, R Z. A medicalização do psíquico: os conceitos de vida e saúde. Arquivos Brasileiros de Psicologia, v. 60, n. 1, p. 124- 13, 2008.

(2012). Sintoma psíquico e medicina baseada em evidências. Arquivos Brasileiros de Psicologia, Rio de Janeiro, v. 64, n. 1, p. 18-30.

CHALMERS, Alan. O que é a ciência afinal? Brasília: Editora Brasiliense, 1999.

DACORSO, S. T. M. Psicanálise e psicanalista: demandas, intervenções e questões. Disponível em: http://www.pepsic.bvsalud.org/pdf/ep/n28/n28a16.pdf. Acesso em 02/03/2014.

ELIA, Luciano. O Conceito de Sujeito. Rio de Janeiro: Jorge Zahar Ed., $3^{\text {a }}$ ed, 2010.

FERRARI, Ilka Franco. A Psicanálise no mundo da ciência. Psicologia em Revista, Belo Horizonte, v. 8, n. 11, p. 82-91, 2002.

FREUD, Sigmund. (1893/1895). Estudos sobre a Histeria. Rio de Janeiro: Imago, 1996. (Edição standard brasileira das obras psicológicas completas de Sigmund Freud, 2). 
(1901/1905). Um caso de histeria, Três ensaios sobre a sexualidade e outros trabalhos. Rio de Janeiro: Imago, 1996. (Edição standard brasileira das obras psicológicas completas de Sigmund Freud, 7, p 76 - 149; 153-159).

(1917/1918). História de uma neurose infantil ["O Homem dos Lobos”] outros textos. Rio de Janeiro: Imago, 1996. (Edição standard brasileira das obras psicológicas completas de Sigmund Freud, 14, p. 15-129).

(1911/1913). O caso Schreber, Artigos sobre a técnica e outros trabalhos. Rio de Janeiro: Imago, 1996. (Edição standard brasileira das obras psicológicas completas de Sigmund Freud, 12, p. 161-187).

JORGE, Juliana David. A construção da associação livre na obra de Freud. Belo Horizonte, 135 págs., Dissertação (Mestrado em Psicologia), PUC- MG, 2007.

LACAN, Jacques. Função e campo da fala e da linguagem em psicanálise. Escritos. Rio de Janeiro, Ed Jorge Zahar, 1953.

MEYER, Catherine. (org). O Livro Negro da Psicanálise. Rio de Janeiro: Civilização Brasileira, $2^{\mathrm{a}}$ ed., 2005.

MILLER, J.; MILNER, J. C. Você quer mesmo ser avaliado? Entrevistas sobre uma máquina de impostura. Baueri, São Paulo: Manole, 2006.

QUINET, Antonio. Psicose e laço social: esquizofrenia, paranoia e melancolia. $2^{\mathrm{a}}$ ed. Rio de Janeiro: Jorge Zahar Ed, 2009.

ROUDINESCO, Elizabeth. Por que a psicanálise? Rio de Janeiro: Ed. Zahar, 2000.

Por que tanto ódio? Anatomia do Livro Negro da Psicanálise. Rio de Janeiro:

Ed. Zahar, 2005.

. Freud-Mas por que tanto ódio?. Rio de Janeiro: Ed. Zahar, 2011a.

. Lacan, a despeito de tudo e de todos.Rio de Janeira: Ed. Zahar, 2011b.

RUSSO, J.; VENÂNCIO, A. T. Classificando pessoas e suas pertubações: a revolução terminológica do DSM III. Revista Latinoamericana de Psicopatologia Fundamental, ano IX, n. 3, 2006. Disponível em www.redalyc.org/articulo.oa?id=233017487007. Acesso em $16 / 05 / 2014$.

$\left.{ }^{[1}\right]_{\text {Revisionista: é o estudo e a reinterpretação da História, baseado na ambiguidade dos fatos históricos e na }}$ imparcialidade com que esses fatos podem ter sido descritos. Segundo muitos autores, $a$ História é uma disciplina ambígua, passível de várias interpretações.

${ }^{[2]}$ Kraftt-Ebbing, Havelock Ellis, para nos restringirmos a dois exemplos. 
Data de recebimento: $25 / 04 / 16$

Data de aceite: $27 / 07 / 16$

\section{Sobre os autores:}

Mayana Bracks é Mestranda do Programa de Pós Graduação da UFSJ. Endereço eletrônico: mayanabracks@gmail.com

Roberto Calazans é Psicanalista. Doutor em Teoria Psicanalítica pela UFRJ. Professor do Programa de Pós-Graduação em Psicologia da UFSJ. Bolsista de Produtividade em Pesquisa, CNPq nível 02. Endereço eletrônico: roberto.calazans@ gmail.com 